\title{
A OPINIÃO SOBRE O ARQUIPÉLAGO DE CHAGOS: A JU- RISDIÇÃO CONSULTIVA DA CORTE INTERNACIONAL DE JUSTIÇA E A NOÇÃO DE CONTROVÉRSIA
}

\author{
THE OPINION ON THE CHAGOS ARCHIPELAGO: THE AD- \\ VISORY JURISDICTION OF THE INTERNATIONAL COURT OF \\ JUSTICE AND THE NOTION OF DISPUTE
}

LuCAs Carlos Lima*

\begin{abstract}
RESUMO
Na opinião consultiva sobre as Consequências jurídicas da Separação do Arquipélago de Chagos de Maurício em 1965 a Corte Internacional de Justiça (CIJ) teve sua jurisdição consultiva contestada pelo fato de existir uma controvérsia pendente entre Reino Unido e a República de Maurício. O presente trabalho analisa os argumentos utilizados pela Corte para superar esta objeção e fundamentar sua jurisdição consultiva. Dois argumentos principais foram utilizados. A Corte alargou o escopo de sua jurisdição a fim de enquadrar sua resposta no quadro amplo de descolonização, anteriormente tratado pela Assembleia Geral. Também foi argumento da Corte o fato de que uma pronúncia do gênero não tocaria numa controvérsia. Realiza-se uma análise das normas que embasam a função consultiva da Corte e a jurisprudência anterior sobre a questão. Sustenta-se que a aplicação dos critérios anteriormente desenvolvidos na jurisprudência no presente caso tem como consequência uma sutil ampliação no escopo da jurisdição consultiva da Corte Internacional de Justiça.
\end{abstract}

PALAVRAS-CHAVE: Corte Internacional de Justiça. Opinião Consultiva. Arquipélago de Chagos.

\begin{abstract}
In the advisory opinion on the Legal Consequences of the Separation of the Chagos Archipelago from Mauritius in 1965, the International Court of Justice (ICJ) had its advisory jurisdiction contested by the fact that it had existed a pending dispute between the United Kingdom and the Republic of Mauritius. The present work analyzes the arguments employed by the Court in order to overcome this objection and to substantiate its advisory jurisdiction. The Court made recourse to two main arguments. The Court has broadened the scope of its jurisdiction with the aim of accommodating its answer within the broader frame of decolonization, previously tackled by the General Assembly. Another argument employed by the Court was the fact that a pronounce of this kind would not touch the issues of a dispute. The work performs an examination of the rules that underlie the Court's advisory function and also the relevant case law. I argue that the application of the criteria previously developed in the Court's case law in the present case has as a consequence a subtle enlargement of the scope of the advisory jurisdiction of the International Court of Justice.
\end{abstract}

KEYWORDS: International Court of Justice. Advisory Opinion. Chagos Archipelago.

\footnotetext{
* Professor adjunto de Direito Internacional da Universidade Federal de Minas Gerais (UFMG). Doutor em Direito Internacional pela Università degli Studi di Macerata. Coordenador do Grupo de Pesquisas em Cortes e Tribunais Internacionais CNPq/UFMG.

E-mail:1clima@ufmg.br.
} 


\section{INTRODUÇÃO}

Em 1997 Sir Robert Jennings, o antigo presidente da Corte Internacional de Justiça ('CIJ' ou 'Corte') escrevia que “certamente juízes devem fazer justiça, mas justiça é precisamente a imparcial aplicação do direito”. ${ }^{1}$ A frase de Jennings de certa forma expressa uma visão mais cautelosa da atividade do juiz, sobretudo do juiz internacional: sua função não é a realização da justiça a qualquer custo, mas a administração do direito tal como está posto. Para os críticos da Corte da Haia, essa visão cautelosa sempre prevaleceu na jurisprudência do principal órgão judiciário da Organização das Nações Unidas ('ONU'). Na recente opinião consultiva emitida pela CIJ em fevereiro de 2019 em sobre as Consequências jurídicas da Separação do Arquipélago de Chagos de Maurício em $1965^{2}$ (doravante 'Chagos' ou 'Arquipélago de Chagos') parece poder-se questionar se a cautela que caracterizava a Corte se fez igualmente presente.

A opinião consultiva requerida pela Assembleia Geral da Organização das Nações Unidas (ONU) à Corte Internacional de Justiça em relação à situação do arquipélago de Chagos insere-se no rol de emblemáticas questões trazidas à barra da Corte da Haia por ser uma das remanescentes questões abertas relativa ao processo de descolonização. ${ }^{3}$ A opinião foi solicitada pela Assembleia Geral numa votação de 94 votos favoráveis a 15 votos contrários - uma reputada derrota para o Reino Unido ${ }^{4}$, o Estado que hoje controla o arquipélago. A segunda derrota para o Reino Unido ocorreu quando da sentença em que por treze votos a um, a CIJ entendeu que o Estado não realizara a descolonização de sua ex-colônia de maneira lídima e, portanto, deveria terminar sua administração do arquipélago de Chagos. ${ }^{5}$ Nos termos bastante diretos da Corte, “o Reino

1 JENNINGS, 1997, p. 36. Do original: "Certainly the judges are to do justice; but justice is precisely the impartial administration of the law".

2 CIJ, Legal consequences of the separation of the Chagos Archipelago from Mauritius in 1965, Advisory Opinion of 25 January 2019.

3 Sobre a questão, ver o GRANT, Thomas D. Regulating the Creation of States from Decolonization to Secession. Journal of International Law and International Relations, vol. 5, afl. 2, 2009, pp. 11-58.. Para uma visão crítica, serve o clássico ANGHIE, Antony. Imperialism, sovereignty and the making of international law. Cambridge: Cambridge University Press, 2005 e o recente ESLAVA, Luis; FAKHRI, Michael; NESIAH, Vasuki. Bandung, Global History and International Law. Cambridge: Cambridge University Press, 2017. Em especial, ver TRINIDAD, Jamie. Self-determination in disputed colonial territories. Cambridge: CUP, 2018. Para uma visão do princípio no interior de uma visão humanizada do direito internacional, ver CANÇADO TRINDADE, Antônio Augusto. International Law for Humankind - Towards a New Jus Gentium. Leiden, Nijhoff, 2013, pp. 1-726.

4 Ver, por exemplo, a matéria "EU members abstain as Britain defeated in UN vote on Chagos Islands" do The Guardian https://www.theguardian.com/world/2017/jun/22/un-vote-backingchagos-islands-a-blow-for-uk.

5 CIJ, 2019, p. 44. 
Unido possui a obrigação de terminar a sua administração do Arquipélago de Chagos o mais rápido possível, deste modo permitindo Maurício completar a descolonização de seu território de uma maneira consistente com o direito dos povos à autodeterminação". ${ }^{6}$

Em brevíssimas palavras, o território relativo a República de Maurício e o arquipélago de Chagos compunham uma unidade administrativa colonial do Território Britânico no Oceano Índico. Em 1965, antes da independência de Maurício em 1968, o Reino Unido separou a zona do arquipélago de Chagos da colônia de Maurício e sistematicamente retirou o povo chagossiano de algumas ilhas, como a ilha de Diego García, onde foi construída uma base militar britânico-americana.

Sendo a descolonização um dos pontos centrais da agenda da ONU, a Assembleia Geral realizou dois questionamentos à CIJ. O primeiro, se a descolonização de Maurício foi completamente legal quando o Estado obteve sua independência. O segundo, sobre as consequências jurídicas de tal ato e a habilidade de Mauricio de realocar seus nacionais, que foram originalmente deportados do arquipélago, de volta às Ilhas. ${ }^{7}$ Como observado por alguns autores ${ }^{8}$, a Assembleia Geral foi particularmente cautelosa em formular as questões de maneira a evitar configurar a consulta como uma controvérsia bilateral entre Reino Unido e Maurício sobre o território de Chagos. Além disso, a Corte foi particularmente percuciente na escolha do direito aplicável para identificar a ilicitude do processo de descolonização. A conclusão da Corte foi que de que o processo de descolonização de Maurício não ocorreu de acordo com o direito internacional. Vez que o desmembramento do Arquipélago de Chagos poucos anos antes da independência de Maurício violava o princípio da integridade territorial e o direito à autodeterminação dos povos - cujo caráter costumeiro foi reafirmado pela Corte, e o caráter de jus cogens discutido por alguns juízes ${ }^{9}-\mathrm{a}$ descolonização ocorrera de maneira não conforme ao direito internacional. Por consequência, a CIJ concluiu que "a contínua administração do Arquipélago de

6 CIJ, 2019, p. 42, para 178.

7 No original, os questionamentos foram: “a) 'Was the process of decolonization of Mauritius lawfully completed when Mauritius was granted independence in 1968, following the separation of the Chagos Archipelago from Mauritius and having regard to international law, including obligations reflected in General Assembly resolutions 1514 (XV) of 14 December 1960, 2066 (XX) of 16 December 1965, 2232 (XXI) of 20 December 1966 and 2357 (XXII) of 19 December 1967?'; (b) 'What are the consequences under international law, including obligations reflected in the above-mentioned resolutions, arising from the continued administration by the United Kingdom of Great Britain and Northern Ireland of the Chagos Archipelago, including with respect to the inability of Mauritius to implement a programme for the resettlement on the Chagos Archipelago of its nationals, in particular those of Chagossian origin?'”. CIJ, 2019, p. 7, para 1.

8 MILANOVIC, 2017, p.1; AKANDE; TZANAPOULOS, 2017, p. 1; CRESPI REGHIZZI, 2018, p. p15.

9 Ver, nesse sentido, as opiniões separadas dos juízes Cançado Trindade, Sebutinde e Robinson. 
Chagos constitui um ato ilícito acarretando a responsabilidade internacional daquele Estado". ${ }^{10}$

$\mathrm{Na}$ opinião consultiva sobre o Arquipélago de Chagos a Corte Internacional de Justiça teve sua jurisdição contestada pelo fato de existir uma controvérsia pendente entre Reino Unido e a República de Maurício. O presente trabalho analisa os argumentos utilizados pela Corte para superar esta objeção e fundamentar sua jurisdição. Dois argumentos principais foram utilizados. A Corte alargou o escopo de sua jurisdição a fim de enquadrar sua resposta no quadro amplo de descolonização, anteriormente tratado pela Assembleia Geral. Também foi argumento da Corte o fato de que uma pronúncia do gênero não tocaria numa controvérsia. Ao se analisar as normas que embasam a função consultiva da Corte e sua jurisprudência anterior sobre a questão, sustenta-se que a consequência da aplicação dos critérios anteriormente desenvolvidos na jurisprudência no presente caso é uma sutil ampliação do escopo da jurisdição consultiva da Corte. Sustenta-se ainda que o entendimento da Corte pode ser lido como um escalonamento de sua função consultiva a despeito de potenciais controvérsias entre Estados. Consequentemente, poder-se-ia sustentar que a Corte arrogou para si um papel ligeiramente maior na revisão de atos internacionais quando assim estipulado pelo órgão da ONU que requereu a opinião. A fim de analisar os dois principais problemas anteriormente apontados, o trabalho estrutura-se da seguinte maneira. Primeiramente (seção 2) analisa-se as principais características da função consultiva da CIJ, bem como a necessidade do consentimento para que a Corte possa analisar uma controvérsia bilateral. Em seguida (seção 3), passa-se a análise do primeiro argumento que a CIJ empregou para responder a esta objeção, qual seja o fato de que o questionamento realizado enquadrava-se num contexto maior no framework da descolonização. O segundo argumento da Corte, de que sua pronúncia não tocaria numa controvérsia bilateral é cotejado posteriormente (seção 4). Tendo feita esta análise, verifica-se se ao empregar estas técnicas no caso concreto a CIJ alargou o escopo de sua jurisdição consultiva (seção 5). Considerações conclusivas são elaboradas (seção 6).

\section{A FUNÇÃO CONSULTIVA DA CORTE INTERNACIONAL DE JUSTIÇA E A OBJEÇÃO SOBRE A EXISTÊNCIA DE UMA CON- TROVÉRSIA BILATERAL}

A função judicial da Corte Internacional de Justiça manifesta-se tanto em seu caráter contencioso quanto consultivo, ambos prescritos pela Carta da Organização das Nações Unidas. ${ }^{11}$ Ambos possuem regimes jurídicos específicos

10 CIJ, 2019, p 42, para 177.

11 Sobre a questão, ver, de maneira ampla HERNÁNDEZ, Gleider I. The International Court of Justice and the judicial function. Oxford: Oxford University Press, 2014. 
delineados nas regras da Corte e em sua jurisprudência. Para que a Corte possa decidir uma controvérsia ou responder a uma opinião consultiva alguns requisitos devem ser observados. Enquanto a função contenciosa está diretamente associada à resolução de controvérsias bilaterais, colocando a CIJ como um meio de solução pacífica de conflitos à disposição dos Estados, a função consultiva conecta a Corte às atividades da Organização das Nações Unidas. ${ }^{12}$ Esta depende, portanto, da solicitação da opinião sobre qualquer questão legal por parte de um dos órgãos autorizados da Organização.

Ao longo de pouco mais de setenta anos de atividade e de 27 opiniões prolatadas, a Corte Internacional de Justiça determinou em sua jurisprudência alguns importantes critérios para o exercício da função consultiva. Esses critérios geralmente foram formulados em resposta a objeções por parte dos Estados. A Corte encontrou oportunidade para esclarecer que a função consultiva é o momento no qual o órgão jurisdicional toma parte nas atividades da organização, ${ }^{13}$ mas que a Corte possui discrição para declinar uma opinião consultiva, se entender que existem razões imperiosas (compelling reasons) que a conduzam nessa direção. ${ }^{14}$ Jamais a Corte recusou-se a responder a um pedido de opinião consultiva, embora já tenha adaptado as perguntas que lhe foram submetidas, como no caso da opinião sobre a Declaração de Independência de Kosovo - argumento que foi levantado por diversos participantes nos procedimentos sobre o Arquipélago de Chagos.

Uma objeção relevante para o presente caso é a existência de uma situação fática correlata com a opinião consultiva que poderia obscurecer as fronteiras entre a função consultiva e a função contenciosa. O posicionamento da Corte tem sido no sentido de privilegiar a função consultiva independentemente dos

12 O artigo 96 da Carta da ONU estabelece a função consultiva da CIJ. Nos artigos 65 a 68 do Estatuto da Corte Internacional de Justiça tal função vem regulada, bem como nos artigos 102 a 109 do Regulamento. A “diretiva prática” número 12 também regulamenta aspectos da função consultiva. Para uma visão geral sobre a função consultiva da Corte, ver DE VISSCHER, Charles, Les avis consultatifs de la Cour permanente de Justice internationale. Recueil des Cours 26, 1929, pp. 1-76; KOLB, Robert. The International Court of Justice. New York: Hart Publishing, 2014; TANCREDI, Antonello. Il parere della Corte internazionale di giustizia sulla dichiarazione d'indipendenza del Kosovo. Rivista di Diritto Internazionale, Vol. 93, 2010, pp. 994-1052; FROWEIN, Jochen; OELLERS-FRAHM. Article 65. in ZIMMERMANN, Andreas; OELLERS-FRAHM, Karin; TOMUSCHAT, Christian; TAMS, Christian J (orgs). The Statute of the International Court of Justice: a commentary. Oxford: Oxford University Press, 2012; ROSENNE, Shabtai. The Law and Practice of the International Court. Leiden: Nijhoff, 2006, pp. 273-254.

13 CIJ, Interpretation of Peace Treaties with Bulgaria, Hungary and Romania, First Phase, Advisory Opinion, I.C.J. Reports 1950, p. 71.

14 CIJ, Legality of the Threat or Use of Nuclear Weapons, Advisory Opinion, I.C.J. Reports 1996, p. 232, para. 10; CIJ, Legal Consequences of the Construction of a Wall in the Occupied Palestinian Territory, Advisory Opinion, I.C.J. Reports 2004, p. 144, para. 13; CIJ, Accordance with International Law of the Unilateral Declaration of Independence in respect of Kosovo, Advisory Opinion, I.C.J. Reports 2010, p. 412, para. 17. 
eventuais impactos que possa ter em controvérsias bilaterais. Como a Corte observara na opinião da Namíbia "diferenças de visões entre Estados sobre questões jurídicas existiram em praticamente todos os procedimentos consultivos". ${ }^{15}$ A jurisprudência recente confirma este antigo dictum. Ao se considerar, por exemplo, a questão da opinião da Construção do Muro no Território Palestino Ocupado ${ }^{16}$ ou a questão da Legalidade da Independência de Kosovo ${ }^{17}$, é possível verificar que ambas estavam relacionadas de alguma maneira com controvérsias pendentes entre os Estados e que, ainda assim, a Corte entendeu exercer sua função consultiva.

É nesse sentido que se estribou a principal e talvez mais contundente linha de argumentação do Reino Unido e de outros Estados participantes no procedimento: a Corte não deveria exercer sua jurisdição consultiva. Segundo o Reino Unido, a Corte, ao responder ao questionamento da Assembleia Geral, estaria extrapolando sua competência consultiva e decidindo sobre uma controvérsia bilateral entre Maurício e Reino Unido - estaria ela adentrando no reino contencioso de sua jurisdição. Como já observado, porque necessário o consenso dos Estados envolvidos para que uma corte internacional possa adjudicar uma controvérsia entre Estados, na ausência desse consenso a República de Maurício estaria contornando o requisito jurisdicional essencial para decidir uma controvérsia territorial. A Corte pontuou no passado que "um Estado não é obrigado a permitir que controvérsias sejam submetidas à solução judicial sem o seu consentimento". ${ }^{18}$

Em suma: para o Reino Unido e outros participantes a República de Maurício estaria usando o procedimento consultivo para resolver uma questão bilateral contenciosa. Parece contar de maneira relevante para esta teoria o fato de que Maurício tentou discutir a questão em processo arbitral constituído sob a Convenção de Direito do Mar, bem como tentou anteriormente trazer o caso perante a própria Corte pela via bilateral. Nas palavras de um dos advogados do Reino Unido, Samuel Wordsworth, “aquilo que Mauricio considerou em 2012 como uma questão para controvérsia bilateral adequada para um procedimento

15 CIJ, Legal Consequences for States of the Continued Presence of South Africa in Namibia (South West Africa) notwithstanding Security Council Resolution 276 (1970), Advisory Opinion, I.C.J. Reports 1971, p. 24, para. 34. Do original: "[d]ifferences of views among States on legal issues have existed in practically every advisory proceeding".

$16 \mathrm{CIJ}$, Legal Consequences of the Construction of a Wall in the Occupied Palestinian Territory, Advisory Opinion, I.C.J. Reports 2004.

$17 \mathrm{CIJ}$, Accordance with International Law of the Unilateral Declaration of Independence in respect of Kosovo, Advisory Opinion, I.C.J. Reports 2010. De maneira geral, ver MILANOVIC, Marko. The law and politics of the Kosovo advisory opinion. Oxford: Oxford University Press, 2015.

18 CIJ, Western Sahara, Advisory Opinion, I.C.J. Reports 1975, pp. 24-25, paras. 32-33. Do original: "a State is not obliged to allow its disputes to be submitted to judicial settlement without its consent". 
contencioso não é absolutamente uma controvérsia bilateral".${ }^{19}$ Embora esta não tenha sido a única objeção por parte do Reino Unido, talvez é aquela com maiores implicações e que seja talvez a mais contestada. É através da resposta a essa argumentação que a Corte parece sutilmente alargar os critérios anteriormente adotados para o exercício da função consultiva.

A resposta da Corte para esquivar-se desta objeção foi bastante breve - talvez até mesmo apressada - e basicamente ancorou-se em duas linhas argumentativas principais. Por primeiro, a Corte salientou que se tratava de um questionamento submetido pela Assembleia Geral da ONU sobre a descolonização. O segundo argumento principal parece ser uma tentativa de não configurar necessariamente a controvérsia no interior da função consultiva. Os argumentos serão analisados em separado.

\section{PRIMEIRO ARGUMENTO: AMPLIANDO O OBJETO DA OPINIÃO OU “NÃO SE TRATA DE QUESTÃO TERRITORIAL, TRATA-SE DE DESCOLONIZAÇÃO"}

Para demonstrar que não estava resolvendo uma controvérsia territorial, a Corte enquadrou a pergunta feita pela Assembleia Geral no âmbito maior da descolonização e do exercício do direito de autodeterminação - assuntos cardinais no trabalho da organização das Nações Unidas e no projeto de direito internacional posterior a $1945 .{ }^{20}$ A estratégia da Corte foi basicamente distanciar-se do problema específico entre os Estados e associar sua jurisdição à matéria envolvendo a questão. Em outras palavras, a Corte do ponto de vista jurisdicional afastou-se da questão da independência em si, mas relacionou seu poder jurisdicional à matéria da descolonização. Tal situação ocorreu somente porque a primeira pergunta foi cunhada pela Assembleia Geral de maneira particularmente aguda:

O processo de descolonização de Maurício estava legalmente completo quando Maurício teve sua independência garantida em 1968, depois da separação do Arquipélago de Chagos de Maurício e em relação ao direito internacional, incluindo as obrigações refletidas nas resoluções da Assembleia Geral 1514 (XV) de 14 de Dezembro de 1960, 2066 (XX) de 16 de Dezembro de 1965, 2232 (XXI) de 20 de Dezembro de 1966 e 2357 (XXII) de 19 de Dezembro de $1967 ?^{21}$

19 CIJ, 2019, Verbatim record 2018/21, p. 27.

20 Ver, nesse sentido CASSESE, Antônio. Self-determination of peoples: a legal reappraisal. Cambridge: Cambridge University Press, 1995 e CRAWFORD, James Richard. The General Assembly, the International Court and self-determination. In LOWE, Vaughan; FITZMAURICE, Malgosia (eds). Fifty years of the International Court of Justice : essays in honour of Sir Robert Jennings. Cambridge: Cambridge University Press, pp. 585-605, bem como ARANGIO-RUIZ, Gaetano. Autodeterminazione dei popoli e diritto internazionale : dalla carta delle Nazioni Unite all'Atto di Helsinki (CSCE). Rivista di studi politici internazionali, vol. 50, 1983, pp. 523-552.

21 CIJ, 2019, p. 32, para 132. Do original: "Was the process of decolonization of Mauritius lawfully completed when Mauritius was granted independence in 1968, following the separation 
A primeira parte da indagação da Assembleia Geral é precisamente formulada no intuito de não requerer qualquer manifestação da Corte Internacional de Justiça sobre controvérsia territorial e, por consequência, sobre uma disputa pendente. Ademais, tal fato se reforça pela formulação da pergunta no tempo pretérito. Trata-se de um controle de legalidade ${ }^{22}$ de fato passado e que, portanto, não se reafirmaria como uma intromissão indevida na bilateralidade de uma disputa pendente. A Assembleia Geral foi particularmente sagaz ao determinar o direito aplicável a ser necessariamente examinado pela Corte. Ao mencionar quatro resoluções de sua própria lavra, a Assembleia interligou a questão com um conteúdo específico de sua responsabilidade, em especial a célebre resolução 1514, denominada "Declaração sobre a Concessão da Independência aos Países e Povos Coloniais”. Nas palavras da própria Corte “a adoção da resolução 1514 (XV) de 14 de dezembro de 1960 representa um momento definidor na consolidação da prática estatal sobre descolonização. (...) A resolução da Assembleia Geral 1514 clarifica o conteúdo e o escopo do direito à autodeterminação.” ${ }^{23}$ Em especial, na sua declaração conjunta, os juízes Cançado Trindade e Robinson são ainda mais contundentes ao observar que a declaração 1514 "cristalizou o direito dos povos à autodeterminação no direito internacional geral”. ${ }^{24} \mathrm{~A}$ CIJ portanto arvora a sua jurisdição consultiva na função da Assembleia Geral em lidar com o problema da descolonização vez que o órgão "possui um longo e consistente histórico de busca pelo fim do colonialismo". ${ }^{25}$ Invocando o precedente da opinião

of the Chagos Archipelago from Mauritius and having regard to international law, including obligations reflected in General Assembly resolutions 1514 (XV) of 14 December 1960, 2066 (XX) of 16 December 1965, 2232 (XXI) of 20 December 1966 and 2357 (XXII) of 19 December 1967?"

22 A expressão "legalidade" no presente trabalho será empregada no sentido de conformidade com as normas jurídicas internacionais. Não se aproxima da noção de legalidade empregada no âmbito doméstico. Ao se referir ao "controle de legalidade" por parte da CIJ, entende-se a verificação por parte da Corte de determinados fatos com os enunciados normativos de regras jurídicas internacionais.

23 CIJ, 2019, p. 35, para 150. Do original: “150. The adoption of resolution 1514 (XV) of 14 December 1960 represents a defining moment in the consolidation of State practice on decolonization. Prior to that resolution, the General Assembly had affirmed on several occasions the right to self-determination (resolutions 637 (VII) of 16 December 1952, 738 (VIII) of 28 November 1953 and 1188 (XII) of 11 December 1957) and a number of non-self-governing territories had acceded to independence. General Assembly resolution 1514 (XV) clarifies the content and scope of the right to self-determination. The Court notes that the decolonization process accelerated in 1960, with 18 countries, including 17 in Africa, gaining independence. During the 1960s, the peoples of an additional 28 non-self-governing-territories exercised their right to self-determination and achieved independence. In the Court's view, there is a clear relationship between resolution 1514 (XV) and the process of decolonization following its adoption."

24 CIJ, 2019, Joint Declaration of Judges Cançado Trindade and Robinson, p. 2, para 4. Do original: "The 1960 Declaration crystallized the right of peoples to self-determination in general international law".

25 CIJ, 2019, p. 23, para. 87. 
do Western Sahara ${ }^{26}$, a Corte entendeu que

a opinião foi requisitada sobre a descolonização, que é uma particular preocupação das Nações Unidas. As questões levantadas pelo pedido estão situadas num quadro mais amplo de referência à descolonização, incluindo o papel da Assembleia Geral nesta, das quais estas questões são inseparáveis ${ }^{27}$.

A ratio por detrás do argumento da Corte é lancinante para garantir sua legitimidade: vez que o assunto em questão está num quadro maior que é, pela Carta da $\mathrm{ONU}^{28}$ e pela prática da organização, um dos principais assuntos da Assembleia, o pedido desse órgão legitima a potencial resposta à questão.

Nesse contexto a objeção por parte de alguns participantes de que a opinião da Corte não iria de maneira alguma auxiliar a Assembleia no exercício de suas funções parece particularmente relevante. Tal argumento parece ter ecoado na declaração individual do juiz Tomka, para quem a Corte estaria dando "um conselho sobre um assunto que a Assembleia Geral não lidou por meio século", ${ }^{29}$ A situação fática parece se distinguir da situação no caso da opinião sobre a Construção do Muro em que a CIJ reconheceu que "a questão da construção do murro no Território Palestino Ocupado foi trazida perante a Assembleia Geral por num número de Estados Membros no contexto da Décima Sessão Especial Emergencial da Assembleia" ${ }^{30}$. A resposta da Corte, todavia, foi igualmente pontual ao restringir o seu campo de análise e determinar que "não é a Corte que determina a utilidade da resposta ao órgão requerente. Pelo contrário, deve ser deixado para o órgão requerente, a Assembleia Geral, a função de terminar se ela precisa da opinião para a própria performance de suas funções". ${ }^{31}$

26 CIJ, Western Sahara, Advisory Opinion, I.C.J. Reports 1975, p. 26, para. 38; Legal Consequences of the Construction of a Wall in the Occupied Palestinian Territory, Advisory Opinion, I.C.J. Reports 2004 (I), p. 159, para. 50.

27 CIJ, 2019, p. 23, para. 88. Do original: “The Court therefore concludes that the opinion has been requested on the matter of decolonization which is of particular concern to the United Nations. The issues raised by the request are located in the broader frame of reference of decolonization, including the General Assembly's role therein, from which those issues are inseparable".

28 A Corte menciona o artigo 1.2 e o artigo 73 para fundamentar essa associação, bem como os trabalhos do Quarto Comitê da Assembleia, que lida com situações políticas e descolonização.

29 CIJ, 2019, Declaration Judge Tomka, p.3, para 6.

30 CIJ, 2004, p. 145, para 17. Do original: "As will be explained below, the question of the construction of the wall in the Occupied Palestinian Territory was brought before the General Assembly by a number of Member States in the context of the Tenth Emergency Special Session of the Assembly, convened to deal with what the Assembly, in its resolution ES-1012 of 25 April 1997 , considered to constitute a threat to international peace and security".

31 CIJ, 2019, p. 20, para 76. Do original: "76. The Court considers that it is not for the Court itself to determine the usefulness of its response to the requesting organ. Rather, it should be left to the requesting organ, the General Assembly, to determine "whether it needs the opinion for the proper performance of its functions" (Accordance with International Law of the Unilateral Declaration of Independence in Respect of Kosovo, Advisory Opinion, I.C.J. Reports 2010 (II), p. 417, para. 34).” 
Superado o argumento, a conclusão que resta é que uma das técnicas utilizadas pela Assembleia Geral e referendada pela Corte neste caso foi a de ampliar o escopo da opinião a fim de desfocar as margens da controvérsia. Embora não seja a primeira vez que a Corte utiliza esta técnica (Caso do Muro e, em certa medida, também na questão da Independência do Kosovo), no presente caso a Corte o fez de maneira mais breve. Uma potencial razão para tal fato seja o caráter não-inovador da doutrina. Adicionalmente, talvez isso explique a razão pela qual o argumento tenha sido acompanhado de uma específica análise de que a pronúncia da Corte não estava associada à controvérsia específica.

\section{SEGUNDO ARGUMENTO: RESPONDER AO QUESTIONA- MENTO DA ASSEMBLEIA NÃO IRÁ TOCAR NA CONTRO- VÉRSIA OU “A CORTE NÃO ESTÁ LIDANDO COM UMA CONTROVÉRSIA"}

Vez que o conceito de controvérsia anteriormente reafirmado pela Corte é específico, parte da argumentação da Corte foi no sentido de não configurar sua pronúncia como a pronúncia sobre uma controvérsia pendente entre Reino Unido e Maurício. Segundo a jurisprudência da CIJ, uma controvérsia é “um desacordo sobre um ponto de direito ou de fato, um conflito de visões legais ou de interesses" 32 entre partes. A argumentação de alguns Estados participantes nos procedimentos foi no sentido de que se a Corte se pronunciasse sobre uma questão em que existia um conflito de visões ou interesses entre dois Estados, ela estaria necessariamente pronunciando-se sobre uma controvérsia. Por consequência, estaria também circunscrevendo o consentimento dos Estados para terem suas controvérsias decididas. A posição da Corte, reafirmando sua anterior jurisprudência de Namibia, foi de

(...) que podem existir diferenças de visões em questões legais em procedimentos consultivos (...). Contudo, o fato que a Corte tenha que se pronunciar em questões legais em que visões divergentes tenham sido expressadas por Maurício

32 CPJI, Mavrommatis Palestine Concessions, Judgment No. 2, 1924, P.C.I.J., Series A, No. 2, p. 11. Do original: "a disagreement on a point of law or fact, a conflict of legal views or of interests". O conceito foi reafirmado em CIJ, South West Africa (Ethiopia v. South Africa; Liberia $v$. South Africa), Preliminary Objections, Judgment, I.C.J. Reports 1962, p. 328; CIJ, Alleged Violations of Sovereign Rights and Maritime Spaces in the Caribbean Sea (Nicaragua v. Colombia), Preliminary Objections, Judgment, I.C.J. Reports 2016. Mais recentemente, a questão da existência de uma controvérsia foi trazida no caso do Desarmamento Nuclear: CIJ, Obligations concerning Negotiations relating to Cessation of the Nuclear Arms Race and to Nuclear Disarmament (Marshall Islands $v$. United Kingdom), Preliminary Objections, Judgment, I.C.J. Reports 2016, p. 833. Sobre a questão ver BONAFÉ, Beatrice Ilaria. Establishing the Existence of a Dispute before the International Court of Justice: Drawbacks and Implications. Questions of International Law. 2017, pp. 3-32 e também LIMA, Lucas Carlos. Da relevância dos casos do desarmamento nuclear perante a Corte Internacional de Justiça. Revista de Direito Internacional, v. 14, p. 203-216, 2018. 
e o Reino Unido não significa que, ao responder a estas questões, a Corte está lidando com uma questão bilateral. ${ }^{33}$

É interessante notar que no enquadrar da questão, a Corte não se pronuncia sobre qualquer questão ou sobre a existência de uma controvérsia, ela parece sugerir a impossibilidade de tocar-se na existência de uma controvérsia. Em verdade, a argumentação da Corte tangencia a existência de uma controvérsia, embora diversos juízes reconheçam a existência de uma disputa entre Reino Unido e Maurício em suas opiniões individuais. ${ }^{34}$ De um ponto de vista lógico, o reconhecimento da existência de uma controvérsia - qualquer que fosse o conteúdo - poderia gerar uma diminuição da legitimidade da resposta da Corte. A separação da função contenciosa e consultiva da Corte é essencial para garantir sua integridade judicial ${ }^{35}$. Esse exercício de toldar de olhos da Corte, contudo, parece pecar no momento em que a Corte se declara ciente do processo arbitral entre Maurício e Reino Unido no âmbito da Convenção das Nações Unidas sobre o Direito do Mar. Sobre a questão, a Corte respondeu que "as questões que foram determinadas pelo Tribunal Arbitral na Arbitragem relativa à Área Marinha Protegida de Chagos não são os mesmos que estão perante a Corte neste procedimento". ${ }^{36}$ Em outras palavras, a Corte declara-se ciente da controvérsia entre os Estados, bem como das posições jurídicas contrastantes dos Estados. Sua pronúncia pode não ser sobre a controvérsia, mas é uma pronúncia ciente da controvérsia e, portanto, também ciente dos potenciais impactos que sua pronúncia pode agir sobre ela.

Nesse sentido, um ponto que chamou particular atenção de alguns juízes em suas opiniões individuais é a decisão da Corte de ter se pronunciado sobre a responsabilidade do Reino Unido. Como observou o juiz Gevorgian, que criticou este comportamento da Corte em sua declaração, embora a Corte o tenha feito no passado, as circunstâncias são diferentes vez que nas vezes anteriores que tenha indicado um ato ilícito por parte de um Estado, o Conselho de Segurança já havia se pronunciado sobre a ilegalidade de situações conexas. Assim, para o juiz russo, “a mencionada declaração de responsabilidade não é apenas sem sentido - já que

33 ICJ, 2019, p. 23, para 89. Do original: "Moreover, the Court observes that there may be differences of views on legal questions in advisory proceedings (Legal Consequences for States of the Continued Presence of South Africa in Namibia (South West Africa) notwithstanding Security Council Resolution 276 (1970), Advisory Opinion, I.C.J. Reports 1971, p. 24, para. 34). However, the fact that the Court may have to pronounce on legal issues on which divergent views have been expressed by Mauritius and the United Kingdom does not mean that, by replying to the request, the Court is dealing with a bilateral dispute".

34 Ver, por exemplo, as declarações e opiniões separadas dos juízes Tomka, Xue, Donoghue.

35 GREENWOOD, 2014, p. 64.

36 CIJ, 2019, para. 81. Do original: "In any event, the Court further notes that the issues that were determined by the Arbitral Tribunal in the Arbitration regarding the Chagos Marine Protected Area (see paragraph 50 above) are not the same as those that are before the Court in these proceedings." 
não está refletida no dispositif e não deveria estar - mas também sem suporte na jurisprudência da Corte" ${ }^{37}$ Em sentido similar, o juiz Tomka entendeu que "procedimentos consultivos não são o fórum apropriado para fazer estes tipos de determinações especialmente quando a Corte não foi solicitada para realizá-los e eles não estritamente necessários para aconselhar o órgão solicitante". ${ }^{38}$ De todo modo, tanto no caso da opinião sobre a Namíbia e na opinião sobre o Muro a Corte Internacional de Justiça estabeleceu específicas consequências para um Estado em virtude do reconhecimento da ilegalidade de um determinado ato ou comportamento no âmbito do direito internacional.

Contudo, a saída da Corte para pronunciar-se sobre a responsabilidade específica do Reino Unido repousa também no fato de que as obrigações em questão são obrigações de natureza erga omnes e não obrigações devidas pelo Reino Unido em relação direta à República de Maurício. Daí a necessidade da Corte de elaborar sobre este ponto. $\mathrm{O}$ fato do direito de autodeterminação dos povos se classificar no rol de "obrigações de um Estado em relação à comunidade internacional como um todo" e que "todos os Estados possuem um interesse jurídico em sua proteção" 39 sugere uma legitimação da pronúncia da Corte. Nesse sentido, é interessante a observação feita pelo juiz Gaja. Na visão do juiz italiano, "se a Corte tivesse escolhido manifestar suas visões sobre questões bilaterais como a alegada existência de uma obrigação para o Reino Unido de fazer reparações a Maurício, uma questão de judicial propriety teria surgido, dada a ausência de consentimento pelos dois Estados envolvidos em relação a uma submissão de controvérsia para a Corte" ${ }^{40}$. O que a opinião do juiz Gaja parece confirmar é que enquanto a Corte não adentrar numa controvérsia exclusivamente bilateral (como a pronúncia sobre reparação) entre Reino Unido e Maurício, está trabalhando no âmbito da integridade judicial de sua função consultiva.

A técnica utilizada pela Corte para fundar sua jurisdição consultiva argumentando que não estava fazendo pronúncias sobre uma controvérsia bilateral não convenceu a juiz Donoghue, que apensou uma opinião dissidente ao

37 CIJ, 2009, Declaration Judge Gevorgian, p. 2, paras 6-7. Do original: "It follows that the above-mentioned statement of responsibility is not only pointless $3 / 4$ it is not reflected in the dispositif, and should not be so $3 / 4$ but also unsupported by the Courts case law.

38 CIJ, 2009, Declaration Judge Tomka, p 3, para 8. Do original: "The Court, despite stating that it is not "dealing with a bilateral dispute" between Mauritius and the United Kingdom, makes an unnecessary pronouncement on "an unlawful act of a continuing character" of the latter in its answer to the second question of the General Assembly (Advisory Opinion, paragraph 177). Advisory proceedings are not an appropriate forum for making these kinds of determinations, especially when the Court is not asked to make them and they are not strictly necessary for providing advice to the requesting organ".

39 CIJ, 1970, p. 32, para 33.

40 CIJ, 2019, Declaration Judge Gaja, p. 3. Do original: "If the Court had chosen to express views on bilateral questions such as the alleged existence of an obligation for the United Kingdom to make reparation to Mauritius, an issue of judicial propriety would have arisen, given the lack of consent of the two States concerned regarding the submission of their dispute to the Court". 
julgamento da Corte. De acordo com a juíza Donoghue, uma série elementos são fundamentais para constatar que existe uma controvérsia pendente entre os Estados. Por exemplo, a tentativa anterior de trazer o caso à Corte, a controvérsia perante o tribunal arbitral constituído sob a UNCLOS e as mudanças na cláusula compromissória da CIJ (Art. 36.2 do Estatuto). Ademais, o argumento da juíza Donoghue vai no sentido de que a centralidade da controvérsia ao assunto da presente opinião faria com que necessariamente a Corte estivesse pronunciando-se sobre uma controvérsia para a qual não havia jurisdição consentida pelos Estados e que, portanto, existiria uma razão imperiosa para a Corte não se pronunciar. De maneira marcante, a juíza Donoghue observou que

a Opinião Consultiva, como seu pedido, evita referências a soberania. Ainda assim, os pronunciamentos da Corte podem significar somente que ela conclui que o Reino Unido possui uma obrigação de liberar sua soberania sobre Maurício. A Corte decidiu a questão que Maurício tentou adjudicar, e que o Reino Unido recusou seu consentimento. ${ }^{41}$

Em defesa dos posicionamentos da Corte em relação à ausência de uma controvérsia e do respeito ao princípio do consentimento, a juíza Xue adota o raciocínio de que em realidade a controvérsia bilateral atual não origina a opinião: é ela própria fruto do processo de descolonização sobre o qual a Corte é chamada a se pronunciar ${ }^{42}$. Ademais, a juíza Xue frisa a questão de que o requerimento da opinião foi verificar a legalidade de um determinado ato num passado específico (os anos de 1965 a 1968, quando da independência de Maurício).

As posições contrastantes dos juízes em suas opiniões individuais oferecem instigante zoom in na câmara de deliberação e sobre os possíveis debates ocorridos no momento de decidir e afirmar a sua jurisdição bem como se existiam razões para duvidar do princípio do consentimento. O fato de que a questão tenha sido levantada em tantas opiniões individuais parece sugerir que a Corte tinha uma decisão significativa a tomar sobre a sua própria função consultiva. É este último ponto que será discutido na última seção do trabalho.

\section{ALARGANDO O ESCOPO DA FUNÇÃO CONSULTIVA DA CIJ?}

As duas técnicas argumentativas utilizadas pela Corte - conexão com a função da AG e não pronúncia sobre uma controvérsia bilateral - conduzem à

41 CIJ, 2019, Dissenting Opinion Judge Donoghue, p. 4, para 19. Do original: “The Advisory Opinion, like the request, avoids references to sovereignty. Yet the Court's pronouncements can only mean that it concludes that the United Kingdom has an obligation to relinquish sovereignty to Mauritius. The Court has decided the very issues that Mauritius has sought to adjudicate, as to which the United Kingdom has refused to give its consent".

42 CIJ, 2019, Declaration Vice-President Xue, p. 5, para 21. A vice-presidente Xue concluiu que "I am convinced that the Court has properly applied the non-circumvention principle in the present proceedings and, by rendering this Advisory Opinion to the General Assembly, has duly discharged its judicial functions entrusted to it by the Charter of the United Nations". 
questão de verificar ter ocorrido ou não um alargamento dos poderes da CIJ em relação a sua função consultiva. Vez que uma controvérsia entre dois Estados parecia existir, havia sido trazida perante outros foros internacionais e alguns juízes sentiram a necessidade de a ela responder, questiona-se se as particulares circunstâncias do presente caso não contribuíram para um alargamento do escopo da função consultiva da Corte Internacional de Justiça.

A questão do consentimento é um problema permanente presente quando tribunais internacionais são requisitados a emanarem opiniões consultivas. ${ }^{43} \mathrm{~A}$ célebre frase de Namíbia em que a Corte parece reconhecer que sempre existiram controvérsias elipsadas por trás das questões consultadas reverbera na literatura e ressoa na presente opinião. ${ }^{44}$ Não se pode evitar a impressão, ao se contrastar a opinião sobre Chagos com a prática precedente relativa a opiniões consultivas, de que existe um tácito reconhecimento por parte da Corte de que questões envolvendo grandes interesses da comunidade internacional, independente de constituírem uma disputa bilateral, devem receber a resposta à solicitação opinião consultiva. Talvez aqui uma consideração de política judiciária possa ser elaborada. Obter a votação de aproximadamente 100 Estados na Assembleia Geral não é um fato isolado tampouco seu mérito deve ser diminuído. Nas duas últimas situações em que isso ocorreu, questões que envolviam grandes interesses da comunidade internacional estavam em jogo.

De um ponto formal, nenhum dos argumentos utilizados pela Corte são necessariamente novos. Contudo, sua aplicação numa situação como a do presente caso, em que a questão não vinha sendo cuidadosamente tratada por parte do Conselho de Segurança ou da Assembleia Geral (como ocorrera no caso do Muro), em que uma das partes envolvidas não estava disposta a cooperar na formulação e pedido da opinião (ex. do caso da Declaração de Kosovo) pode gerar consequências distintas.

É bem verdade que a principal limitação imposta à atividade consultiva da Corte é formulada pelos limites da Carta da ONU e do Estatuto da CIJ. O limite à pergunta formulada pela Assembleia é data pelo artigo 96 da Carta que determina que “a Assembleia Geral ou o Conselho de Segurança podem solicitar à Corte Internacional de Justiça uma opinião consultiva em qualquer questão jurídica (legal question)". ${ }^{45}$ A expressão “questão jurídica” oferece uma ampla

43 KOLB, 2014, p. No que se refere ao Tribunal Internacional do Direito do Mar, ver MAROTTI, Loris. Sulla funzione consultiva del Tribunale internazionale del diritti del mare. Rivista di Diritto Internazionale, vol. 98, 2015, pp. 1171-1197 e LANDO, Massimo. The Advisory Jurisdiction of the International Tribunal for the Law of the Sea: Comments on the Request for an Advisory Opinion Submitted by the Sub-Regional Fisheries Commission. Leiden Journal of International Law, Vol 29, 2016, pp. 441-461.

44 KOLB, 2014, p. 1013.

45 Do original: "The General Assembly or the Security Council may request the International Court of Justice to give an advisory opinion on any legal question". 
margem de ação para a Corte no momento de decidir pronunciar-se ou não. No atual estado do direito internacional dificilmente uma dissidência de opiniões entre Estados não poderia ser formulada em questões jurídicas. Como notado por um célebre autor em relação ao pacto da Liga das Nações, a expressão “questão jurídica" engloba a noção de controvérsia ${ }^{46}$ e a história dos procedimentos da Corte Permanente de Justiça Internacional demonstram que a jurisdição consultiva nasce em relação a opiniões "não obrigatórias" para controvérsias pendentes. ${ }^{47}$ Uma leitura do artigo 96 com o artigo 10 da Carta da ONU, que estabelece as competências da Assembleia Geral como “quaisquer questões ou assuntos que estiverem dentro das finalidades da presente Carta ou que se relacionarem com as atribuições e funções de qualquer dos órgãos nela previstos" ${ }^{48}$, permite vislumbrar uma ampla possibilidade da Assembleia Geral submeter situações ao controle de legalidade da Corte. Nesse sentido, reproduzindo os termos do artigo 96, a Corte na opinião sobre o Arquipélago de Chagos pontuou que:

A Corte considera que uma solicitação da Assembleia Geral por uma opinião consultiva para examinar uma situação em referência ao direito internacional constitui uma questão jurídica (legal question). ${ }^{49}$

Esta frase é interessante não apenas porque classifica a situação envolvendo Chagos como uma questão jurídica. Ela é igualmente interessante porque a Corte sedimenta a função consultiva da Corte Internacional de Justiça como uma espécie de controle de conformidade com o direito internacional - algo que, de certa forma, já ocorrera na opinião sobre a Legalidade da Ameaça ou Uso de Armas Nucleares ${ }^{50}$, na questão da Construção do Muro na Palestina ${ }^{51} \mathrm{e}$ na questão da Declaração da Independência do Kosovo..$^{52}$ Em especial, a Corte

46 KELSEN, 1939, p.119.

47 Sobre a questão, ver DE VISSCHER, 1929, p. 13; HUDSON, 1943, p. 512 e KOLB, 2014, p. 1011.

48 CARTA DA ONU, 1945, Artigo 10. Do original: “The General Assembly may discuss any questions or any matters within the scope of the present Charter or relating to the powers and functions of any organs provided for in the present Charter, and, except as provided in Article 12, may make recommendations to the Members of the United Nations or to the Security Council or to both on any such questions or matters".

49 CIJ, 2019, Do original: “The Court considers that a request from the General Assembly for an advisory opinion to examine a situation by reference to international law concerns a legal question".

50 CIJ, 1996, p. 238. Na ocasião, a pergunta da Assembleia Geral à Corte foi formulada da seguinte maneira: "Is the threat or use of nuclear weapons in any circumstance permitted under international law?"

51 CIJ, 2004, p. 141. Na ocasião, a pergunta da Assembleia à Corte foi: "What are the legal consequences arising from the construction of the wall being built by Israel, the occupying Power, in the Occupied Palestinian Territory, including in and around East Jerusalem, as described in the report of the Secretary-General, considering the rules and principles of international law, including the Fourth Geneva Convention of 1949, and relevant Security Council and General Assembly resolutions?"

52 CIJ, 2010, p. 407. A pergunta da Assembleia na ocasião foi: “'Is the unilateral declaration of 
observou na opinião da independência do Kosovo que "uma questão que expressamente questiona a Corte se uma ação particular é compatível com o direito internacional certamente parece ser uma questão jurídica" 53 e que, como havia já pontuado na opinião do Saara Ocidental questões “formuladas em termos jurídicos e levantando problemas de direito internacional (...) são pela sua própria natureza suscetíveis de serem respondias com base no direito". ${ }^{54}$

A distinção é que, nos casos anteriores, o objeto não parecia ser tão conectado à uma disputa bilateral e que pudesse tocar intimamente o território de um Estado. Enquanto na questão das Armas Nucleares a pergunta era ampla e genérica em relação ao uso de determinado tipo de armamento, e na questão da independência de Kosovo o ato controlado era a declaração realizada pelas instituições provisórias do Estado, mesmo na questão do Muro a manifestação sobre o controle de legalidade não impactaria os interesses representados pela extensão territorial de um Estado. $\mathrm{Na}$ presente opinião, a Corte está ciente de que sua pronúncia significa que a disputa territorial em relação ao arquipélago de Chagos implica uma posse ilegal por parte do Reino Unido.

Do ponto de vista processual, é difícil não perceber a atitude da Corte como uma espécie de escalonamento funcional de sua atividade judicial. Na medida em que a Assembleia Geral lhe submeter uma questão para que seja realizado um controle de legalidade, o fato de que a pronúncia possa afetar uma controvérsia no centro da matéria não é uma razão imperiosa para que a Corte não se pronuncie. A função consultiva, uma das maneiras pelas quais a CIJ assume sua função como parte da Organização, parece sobrepor-se à potencial função contenciosa que depende do consentimento dos Estados. Com tal posicionamento, reforçado na opinião do Arquipélago de Chagos, a Corte rememora que é no âmbito da Assembleia Geral que permanece a decisão de submeter ou não uma controvérsia pendente perante o principal órgão judiciário das Nações Unidas.

\section{REFLEXÕES CONCLUSIVAS}

Diferentemente dos julgamentos da Corte, opiniões consultivas não são obrigatórias e não vinculam os Estados; ${ }^{55}$ elas representam a visão do direito por parte de um prestigioso tribunal internacional. A opinião é oferecida à ONU e

independence by the Provisional Institutions of Self-Government of Kosovo in accordance with international law?"”

53 CIJ, 2010, p. 415. Do original: "A question which expressly asks the Court whether or not a particular action is compatible with international law certainly appears to be a legal question".

54 CIJ, 1975, p 18. Do original: "framed in terms of law and rais[ing] problems of international law ... are by their very nature susceptible of a reply based on law".

55 Construção determinada pelo Artigo 59 do Estatuto da Corte Internacional de Justiça, que estabelece que "the decision of the Court has no binding force except between the parties and in respect of that particular case". 
não aos Estados. ${ }^{56}$ Em última análise, é o consentimento que rende o julgamento obrigatório aos litigantes. Contudo, como bem ilustrou o juiz Gros em sua declaração no caso do Western Sahara "quando a Corte oferece uma opinião consultiva numa questão de direito, ela declara o direito. A ausência de força obrigatória não transforma a operação judicial numa consulta legal, que pode ser usado ou não de acordo com a escolha". ${ }^{57}$ No caso presente, ainda que não obrigatória, a Corte declarou a ilicitude da separação do arquipélago de Chagos de Maurício bem como declarou a necessidade de se por fim ao fato ilícito. Esta informação não poderá ser negligenciada nas futuras negociações entre Reino Unido e Maurício, tampouco poderá sê-lo por Estados terceiros vez que a Corte declarou que "todos os Estados membros [da ONU] estão sob uma obrigação de cooperar com as Nações Unidas de maneira a completar a descolonização de Maurício" ${ }^{58}$.

De uma maneira geral, a Corte faz considerações extremamente importantes nesta opinião consultiva. Ela desfere golpe necessário em práticas colonizadoras: não importa quando elas ocorreram, elas não podem gerar efeitos jurídicos na atualidade. A ordem jurídica internacional repele essa ilegalidade através da incidência de duas normas de fundamental importância, a integridade territorial e autodeterminação dos povos.

Embora os argumentos aplicados pela Corte não sejam necessariamente novos, as circunstâncias do presente caso levam a concluir que as posições assumidas pela Corte alargaram sutilmente a margem de ação dentro de sua jurisdição consultiva. O principal órgão judiciário da Organização das Nações Unidas reitera sua posição de verificador de conformidade com o direito internacional, mesmo quando uma controvérsia repousa nas margens (ou ao centro, a depender do observador) do objeto da opinião. Somente a prática futura da Corte poderá confirmar se se trata de uma tendência de ampliação dos poderes da Corte e da assunção de uma posição mais central nas controvérsias internacionais através de sua função consultiva. Esta prática dependerá, essencialmente, dos posicionamentos dos Estados na Assembleia Geral em relação às questões jurídicas que submeterem à apreciação da Corte Internacional de Justiça.

56 CIJ, Interpretation of Peace Treaties case, ICJ Reports 1950, pp. 65, para 74.

57 CIJ, 1975, Declaration of Judge Gros, p. 73, para 6. Do original: "Je rappellerai seulement que la Cour, lorsqu'elle rend un avis consultatif sur une question de droit, dit le droit. Je rappellerai seulement que la Cour, lorsqu'elle rend un avis consultatif sur une question de droit, dit le droit. L'absence de force obligatoire ne transforme pas la démarche judiciaire en consultation juridique qu'on utilise ou non à sa guise. L'avis consultatif détermine le droit applicable à la question posée; il est possible que l'organe qui a demandé I'avis ne le suive pas dans son action, mais cet organe sait qu'il ne pourrait adopter une position contraire au prononcé de la Cour avec une efficacité quelconque sur le plan juridique".

58 CIJ, 2019, p. 44, dispositif. Do original: "The Court, by thirteen votes to one, is of the opinion that all Member States are under an obligation to co-operate with the United Nations in order to complete the decolonization of Mauritius." 


\section{REFERÊNCIAS}

AGO, Roberto. I pareri consultivi “vincolanti” della Corte Internazionale di Giustizia. Rivista di Diritto Internazionale, Vol. 73, 1990, pp. 5-23.

AKANDE, Dapo. The competence of international organizations and the Advisory Jurisdiction of the International Court of Justice. European Journal of International Law, vol. 9, 1998, pp. 437-467.

AKANDE, Dapo; TZANAPOULOS, Antonios. Can the International Court of Justice Decide on the Chagos Islands Advisory Proceedings without the UK's Consent? EJILTalk, 27 Junho 2017. Disponível em: <https:/www.ejiltalk.org/ can-the-international-court-of-justice-decide-on-the-chagos-islands-advisoryproceedings-without-the-uks-consent/>.

ANGHIE, Antony. Imperialism, sovereignty and the making of international law. Cambridge: Cambridge University Press, 2005.

ARANGIO-RUIZ, Gaetano. Autodeterminazione dei popoli e diritto internazionale: dalla carta delle Nazioni Unite all'Atto di Helsinki (CSCE). Rivista di studi politici internazionali, vol. 50, 1983, pp. 523-552.

BONAFÉ, Beatrice Ilaria. Establishing the Existence of a Dispute before the International Court of Justice: Drawbacks and Implications. Questions of International Law. 2017, pp. 3-32.

BONAFE, Beatrice Ilaria. "La Cour internationale de Justice et la notion de différent”. Ordine internazionale e diritti umani, Vol. 5, pp. 924-933, 2016.

BROWN, Chester. A common law of international adjudication. Oxford: Oxford University Press, 2007.

CANÇADO TRINDADE, Antônio Augusto. International Law for Humankind - Towards a New Jus Gentium. Leiden, Nijhoff, 2013, pp. 1-726.

CASSESE, Antônio. Self-determination of peoples: a legal reappraisal. Cambridge: Cambridge University Press, 1995.

CORTE INTERNACIONAL DE JUSTIÇA. Accordance with International Law of the Unilateral Declaration of Independence in respect of Kosovo, Advisory Opinion, I.C.J. Reports 2010.

CORTE INTERNACIONAL DE JUSTIÇA. Alleged Violations of Sovereign Rights and Maritime Spaces in the Caribbean Sea (Nicaragua v. Colombia), Preliminary Objections, Judgment, I.C.J. Reports 2016.

CORTE INTERNACIONAL DE JUSTIÇA. Barcelona Traction, Light and Power Company, Limited, Judgment, I.C.J. Reports 1970. 
CORTE INTERNACIONAL DE JUSTIÇA. Interpretation of Peace Treaties with Bulgaria, Hungary and Romania, First Phase, Advisory Opinion, I.C.J. Reports 1950.

CORTE INTERNACIONAL DE JUSTIÇA. Interpretation of Peace Treaties case, ICJ Reports 1950.

CORTE INTERNACIONAL DE JUSTIÇA. Legal Consequences for States of the Continued Presence of South Africa in Namibia (South West Africa) notwithstanding Security Council Resolution 276 (1970), Advisory Opinion, I.C.J. Reports 1971.

CORTE INTERNACIONAL DE JUSTIÇA. Legal Consequences of the Construction of a Wall in the Occupied Palestinian Territory, Advisory Opinion, I.C.J. Reports 2004.

CORTE INTERNACIONAL DE JUSTIÇA. Legal consequences of the separation of the Chagos Archipelago from Mauritius in 1965, Advisory Opinion of 25 January 2019.

CORTE INTERNACIONAL DE JUSTIÇA. Legality of the Threat or Use of Nuclear Weapons, Advisory Opinion, I.C.J. Reports 1996.

CORTE INTERNACIONAL DE JUSTIÇA. Obligations concerning Negotiations relating to Cessation of the Nuclear Arms Race and to Nuclear Disarmament (Marshall Islands v. United Kingdom), Preliminary Objections, Judgment, I.C.J. Reports 2016.

CORTE INTERNACIONAL DE JUSTIÇA. South West Africa (Ethiopia v. South Africa; Liberia v. South Africa), Preliminary Objections, Judgment, I.C.J. Reports 1962.

CORTE INTERNACIONAL DE JUSTIÇA. Western Sahara, Advisory Opinion, I.C.J. Reports 1975.

CORTE INTERNACIONAL DE JUSTIÇA. Legality of the Threat or Use of Nuclear Weapons. Advisory Opinion. ICJ Reports 1996.

CORTE INTERNACIONAL DE JUSTIÇA. Nuclear Tests (New Zealand v. France). ICJ Reports 1974.

CORTE PERMANENTE DE JUSTIÇA INTERNACIONAL. Affaire des Concessions Mavrommatis en Palestine, CPJI, Series A, No. 2, 1924.

CRAWFORD, James Richard. The General Assembly, the International Court and self-determination. In: LOWE, Vaughan; FITZMAURICE, Malgosia (eds). Fifty years of the International Court of Justice: essays in honour of Sir Robert Jennings. Cambridge: Cambridge University Press, pp. 585-605. 
CRESPI REGHIZZI, Zeno. La juridiction consultative à l'épreuve du principe consensuel: l'affaire des Effets juridiques de la séparation de l'archipel des Chagos de Maurice en 1965. Questions of International Law, Zoom-out 55, Nov 2018, pp. 15-34.

DE VISSCHER, Charles, Les avis consultatifs de la Cour permanente de Justice internationale. Recueil des Cours 26, 1929.

ESLAVA, Luis; FAKHRI, Michael; NESIAH, Vasuki. Bandung, Global History and International Law. Cambridge: Cambridge University Press, 2017.

FORLATI, Serena. The International Court of Justice: an arbitral tribunal or a judicial body? New York: Springer, 2014.

FROWEIN, Jochen; OELLERS-FRAHM. Article 65. In: ZIMMERMANN, Andreas; OELLERS-FRAHM, Karin; TOMUSCHAT, Christian; TAMS, Christian J (orgs). The Statute of the International Court of Justice: a commentary. Oxford: Oxford University Press, 2012.

GAJA, Giorgio. Interpreting Articles Adopted by the International Law Commission. The British Yearbook of International Law, Vol. 85, 2014, pp.10-20.

GRANT, Thomas D. Regulating the Creation of States from Decolonization to Secession. Journal of International Law and International Relations, vol. 5, afl. 2, 2009.

GREENWOOD, Cristopher. Judicial Integrity and the Advisory Jurisdiction of the International Court of Justice. In: GAJA, Giorgio; STOUTENBURG, Grote. Enhancing the Rule of Law through the International Court of Justice. Leiden: Nijhoff, 2014, pp. 63-75.

HERNÁNDEZ, Gleider I. The International Court of Justice and the judicial function. Oxford: Oxford University Press, 2014.

HIGGINS, Rosalyn. The advisory opinion on Namibia: which UN resolutions are binding under article 25 of the charter. The International and Comparative Law Quarterly, Vol. 21, No. 2, 1972, pp. 270-286.

HUDSON, Manley O. The Permanent court of international justice, 1920-1942: a treatise. New York: The Macmillan company, 1943.

JENNINGS, Robert Y. The Role of the International Court of Justice. British Yearbook of International Law, Volume 68, 1997, pp. 1-63, p.39.

KELSEN, Hans. Legal technique in International Law: a textual critique of the League Covenant. Genebra: Geneva Research Center ,1939.

KLABBERS, Jan. Shrinking Self-determination: The Chagos Opinion of the International Court of Justice. ESIL Reflections. Volume 8, Issue 2, 2019, pp. 1-9. 
KOLB, Robert. The International Court of Justice. New York: Hart Publishing, 2014.

LANDO, Massimo. The Advisory Jurisdiction of the International Tribunal for the Law of the Sea: Comments on the Request for an Advisory Opinion Submitted by the Sub-Regional Fisheries Commission. Leiden Journal of International Law, Vol 29, 2016, pp. 441-461.

LIMA, Lucas Carlos. Da relevância dos casos do desarmamento nuclear perante a Corte Internacional de Justiça. Revista de Direito Internacional, v. 14, p. 203 216, 2018.

MAROTTI, Loris. Sulla funzione consultiva del Tribunale internazionale del diritto del mare. Rivista di Diritto Internazionale, vol. 98, 2015, pp. 1171-1197.

MAROTTI, Loris. The International Court of Justice Role in Influencing the Approach of other Courts on Fundamental Procedural Matters. In: ARCARI, Maurizio; BALMOND, Louis. (orgs). Le dialogue des juridictions dans l'ordre juridique international: entre pluralisme et sécurité juridique. Napoli: Editoriale Scientifica, 2014, pp.7-27.

MERKOURIS, Panos. The Advisory Jurisdiction of the Permanent Court of International Justice in Practice: a Tale of two Scopes. In: TAMS, Christian J; FITZMAURICE, Malgosia (eds). Legacies of the Permanent Court of International Justice. Leiden: Nijhoff, 2013.

MILANOVIC, Marco. ICJ Advisory Opinion Request on the Chagos Islands. EJILTalk, 24 de Junho de 2017. Disponível em: <https:/www.ejiltalk.org/icjadvisory-opinion-request-on-the-chagos-islands/>.

MILANOVIC, Marko (ed.). The law and politics of the Kosovo advisory opinion. Oxford: Oxford University Press, 2015.

ROSENNE, Shabtai. The Law and Practice of the International Court. Leiden: Nijhoff, 2006, pp. 273-254.

SUMMERS, James. Peoples and International Law: How Nationalism and Self-Determination Shape a Contemporary Law of Nations. Leiden: Martinus Nijhoff, 2007.

TANCREDI, Antonello. Il parere della Corte internazionale di giustizia sulla dichiarazione d'indipendenza del Kosovo. Rivista di Diritto Internazionale, Vol. 93, 2010, pp. 994-1052.

TRINIDAD, Jamie. Self-Determination and territorial integrity in the Chagos Advisory Proceedings: Potential broader ramifications. Questions of International Law, Zoom Out 55, 2018, pp. 61-69. 
TRINIDAD, Jamie. Self-determination in disputed colonial territories. Cambridge: CUP, 2018.

WOOD, Michael. Advisory Jurisdiction: Lessons from Recent Practice. In: HESTERMEYER, Holget et al (eds). Coexistence, Cooperation and Solidarity: liber amicorum Rüdiger Wolfrum. Nijhoff: 2012, pp. 1833-1849.

YEE, Sienho. Notes on the International Court of Justice (Part 7) - The Upcoming Separation of the Chagos Archipelago Advisory Opinion: Between the Court's Participation in the UN's Work on Decolonization and the Consent Principle in International Dispute Settlement. Chinese Journal of International Law, vol. 16, 2017, pp. 623-642.

Recebido em: 10/04/2019.

Aprovado em: 24/09/2019. 